BMJ Open

Diabetes

Research

\& Care

\section{Dietary intake of adults with and without diabetes: results from NHANES 2013-2016}

To cite: McClure ST, Schlechter $\mathrm{H}, \mathrm{Oh} \mathrm{S}$, et al. Dietary intake of adults with and without diabetes: results from NHANES 2013-2016. BMJ Open Diab Res Care 2020;8:e001681. doi:10.1136/ bmjdrc-2020-001681

- Supplemental material is published online only. To view, please visit the journal online (http://dx.doi.org/10.1136/ bmjdrc-2020-001681).

Received 12 June 2020 Revised 4 September 2020 Accepted 23 September 2020

Check for updates

\section{(C) Author(s) (or their} employer(s)) 2020. Re-use permitted under CC BY-NC. No commercial re-use. See rights and permissions. Published by BMJ.

For numbered affiliations see end of article.

Correspondence to Dr Scott T McClure; smcclure@su.edu

\section{ABSTRACT}

Introduction Diet is a critical aspect of the management of adults with diabetes. This paper aims to compare dietary intakes of key macronutrients and micronutrients of US adults with and without diabetes and across the spectrum of diabetes.

Research design and methods We compared absolute and energy-adjusted dietary intake of major macronutrients and micronutrients among those with and without diabetes and across the spectrum of glycemic control using a 24-hour dietary recall from a crosssectional, nationally representative sample of 9939 US adults, 20+ years old (National Health and Nutrition Examination Survey 2013-2016). Diabetes was defined as an glycohemoglobin $\mathrm{A} 1 \mathrm{c}(\mathrm{HbA1c}) \geq 6.5 \%$, fasting glucose $\geq 126 \mathrm{mg} / \mathrm{dL}$, serum glucose at 2 hours following a $75 \mathrm{~g}$ glucose load (oral glucose tolerance test) $\geq 200 \mathrm{mg} / \mathrm{dL}$, any diagnosis of diabetes or use of diabetes medication (selfreported).

Results Percent of calories from macronutrients was similar for those with and without diabetes ( $p>0.05$, energy adjusted and adjusted for age, race, and sex). In both groups, sugar accounted for about $20 \%$ of calories. Those with diabetes consumed about $7 \%$ more calcium ( $p=0.033)$, about $5 \%$ more sodium $(p=0.026)$, and had lower diet quality (Healthy Eating Index-2015, $p=0.021$ ) than those without diabetes. Among those with diabetes, those with an $\mathrm{HbA} 1 \mathrm{c}>9.0 \%$ consumed about $4 \%$ less magnesium ( $p$-analysis of variance $=0.007$ ) than those with an $\mathrm{HbA} 1 \mathrm{c}<6.5 \%$. Results were similar within strata of age, race, and sex. Macronutrient intake did not vary consistently by $\mathrm{HbA} 1 \mathrm{c}$ level.

Conclusions In this nationally representative sample, there were no substantial or consistent differences in the dietary intake of macronutrients or micronutrients between US adults with and without diabetes. Improving the diets of those with diabetes will likely require enhanced targeted efforts to improve the dietary intake of persons with diabetes, as well as broad efforts to improve the dietary intake of the general population.

\section{INTRODUCTION}

Improved nutrition is critical to preventing and managing type 2 diabetes. The American Diabetes Association (ADA) notes that, while diet alone may not be sufficient to manage

\section{Significance of this study}

What is already known about this subject?

> Improved nutrition is critical to preventing and managing type 2 diabetes.

- It has been well established that US adults (regardless of diabetes status) do not meet US dietary guidelines.

- It remains unclear, however, whether dietary intakes differ by diabetes status, and whether there are differences in intake by hemoglobin A1c.

What are the new findings?

- In this nationally representative sample, there were no substantial or consistent differences in the dietary intake of macronutrients or micronutrients between US adults with and without diabetes.

- Those with diabetes had slightly lower diet quality overall based on the Healthy Eating Index-2015.

- Those with diabetes were less likely to have full food security, with fewer than half of those with hemoglobin A1c $>9.0 \%$ having full food security.

How might these results change the focus of research or clinical practice?

- Improving the diets of those with diabetes will likely require enhanced targeted efforts to improve the dietary intake of persons with diabetes, as well as broad efforts to improve the dietary intake and food security of the general population.

type 2 diabetes, it is an 'important component' of care. ${ }^{1}$ The current dietary recommendations for those with diabetes are similar to the general population, emphasizing nutrientdense foods and healthful dietary patterns. ${ }^{1-3}$ The 2020 ADA recommendations encourage consuming non-starchy vegetables, minimizing refined grains and added sugars, and consuming whole foods rather than highly processed ones. ${ }^{3}$ While there is no ideal target for macronutrient ratios among those with diabetes, reducing total carbohydrate intake may improve glycemia. ${ }^{3}$ 
It has been well established that US adults (regardless of diabetes status) do not meet US dietary guidelines (including the US Department of Agriculture (USDA) Dietary Guidelines for Americans and the American Heart Association targets) ${ }^{45}$ It remains unclear, however, whether dietary intakes differ by diabetes status, and whether there are differences in intake by hemoglobin A1c. An analysis of cross-sectional data from China found some small but statistically significant differences in the diets of those with and without type 1 diabetes, but did not examine those with type 2 diabetes. ${ }^{6}$ Further understanding of the differences, or lack thereof, in the dietary intake of US adults with and without diabetes could inform dietary recommendations, nutrition interventions, and broader food policies aimed at improving the diet of those with diabetes.

The objective of this paper is to compare dietary intakes of key macronutrients and micronutrients that impact cardiometabolic disease of US adults with and without diabetes and across the spectrum of diabetes. ${ }^{7}$ We analyzed both energy-adjusted and absolute intake using data from the National Health and Nutrition Examination Survey (NHANES)-What We Eat in America (NHANES-WWEIA) cycles from 2013 to 2016.

\section{MATERIALS AND METHODS}

We used data from two cycles (2013-2014 and 2015-2016) of the NHANES. NHANES is a nationally representative cross-sectional survey of the US population consisting of a dietary intake interview portion (WWEIA), laboratory measurements, physical examinations, and medical and non-medical questionnaires. We included 4299 participants (representing 217296304 people) who were 20 years of age or older, not pregnant, had one complete 24-hour dietary interview, and had fasted for at least 8 hours but less than 24 hours at the time of the laboratory examination. Nutrient intake was estimated from a single in-person 24-hour dietary intake interview linked to a nutrient database. Serum fasting glucose, glycohemoglobin A1c (HbAlc), and other variables (cholesterol) were obtained from fasting serum samples taken by venipuncture. Following this fasting specimen collection, participants consumed $75 \mathrm{~g}$ of dextrose followed by a second serum sample 2 hours later for the oral glucose tolerance test (OGTT). Blood pressure was measured after a $5 \mathrm{~min}$ rest in the seated position. Three consecutive blood pressure measurements were taken. Selfreported history of diabetes diagnosis, insulin use, and other medication use was obtained by a medical history questionnaire administered by trained study personnel.

\section{Diabetes}

In the main analysis, we defined diabetes as any of the following: $\mathrm{HbAl} \mathrm{c} \geq 6.5 \%$, serum glucose at 2 hours following a $75 \mathrm{~g}$ glucose load (OGTT) $\geq 200 \mathrm{mg} / \mathrm{dL}$, fasting glucose $\geq 126 \mathrm{mg} / \mathrm{dL}$, any self-reported diagnosis of diabetes, or any self-reported use of insulin or other diabetes medication. ${ }^{8}$ Time since diabetes diagnosis was calculated by subtracting participants' current age from self-reported age at diagnosis, or zero for those diagnosed during the NHANES examination.

In the secondary analysis, we used the same definition of diabetes, but further categorized by HbA1c level: normal (no diabetes and $\mathrm{HbAlc}<5.7 \%$ ), pre-diabetes (no diabetes and $\mathrm{HbA} 1 \mathrm{c} \geq 5.7 \%$ and $<6.5 \%$ ), diabetes without elevated HbAlc (HbAlc $<6.5 \%)$, diabetes with elevated HbAlc (HbAlc $\geq 6.5 \%$ and $<9.0 \%$ ), diabetes with very elevated HbAlc (HbA1c $\geq 9.0 \%)$.

\section{Dietary intake and other covariates}

We calculated the dietary intake of macronutrients and micronutrients from single 24-hour recalls. Investigated nutrients affect cardiometabolic health, including macronutrients and micronutrients. The latter include certain micronutrients (eg, potassium, magnesium, calcium and sodium) potentially relevant to diabetes and associated comorbidities, such as hypertension..$^{239-11}$ Diet quality was estimated from 0 (worst) to 100 (best) using the Healthy Eating Index based on the 2010-2015 Dietary Guidelines for Americans (HEI-2015). ${ }^{12-14}$ Self-reported food security was categorized as full food security for participants with no affirmative responses on the food security questionnaire. ${ }^{15}$ Those with at least one affirmative response were categorized as marginal to very low food security. Self-reported access to healthcare was defined as having at least one place the participant usually goes to when sick or needs health advice.

Serum samples were analyzed for total cholesterol, highdensity lipoprotein (HDL) cholesterol, and triglycerides. Low-density lipoprotein (LDL) cholesterol was then calculated using the Friedewald equation. ${ }^{16}$ The mean of all available measurements was reported for systolic and diastolic blood pressure. Self-reported education level was categorized as less than or equal to a high school diploma, or greater than a high school diploma. Income was categorized as less than three times the poverty line or greater than or equal to three times the poverty line. The ratio of family income to poverty was calculated using self-reported family income and the yearly Department of Health and Human Services poverty guidelines.

\section{Statistical analysis}

Appropriate 4-year survey weights were used to account for NHANES multistage design and the use of two NHANES cycles (2013-2014 and 2015-2016). Four-year mean dietary intakes were reported as absolute and energy adjusted using marginal estimates from linear regression. Models were adjusted for age (continuous), race (nonHispanic white, non-Hispanic black, Mexican American, and other), and sex. Energy adjustment for macronutrients was performed by calculating the percent of total energy intake from a given nutrient. Total carbohydrate, sugar, and protein were multiplied by $4 \mathrm{kcal} / \mathrm{g}$ and total fat, saturated fat, polyunsaturated fat, and monounsaturated fat were multiplied by $9 \mathrm{kcal} / \mathrm{g}$. Energy adjustment 
Table 1 Demographic and medical characteristics by diabetes states of non-pregnant adults 20+ years old from NHANES 2013-2016*

\begin{tabular}{|c|c|c|c|}
\hline & No diabetes & Diabetes & $P$ value \\
\hline n (unweighted) & 3352 & 947 & \\
\hline \multicolumn{4}{|l|}{ Sex } \\
\hline Male (\%) & 48.1 (46.4 to 49.8$)$ & 51.7 (47.7 to 55.7$)$ & 0.113 \\
\hline Female (\%) & 51.9 (50.2 to 53.6$)$ & 48.3 (44.3 to 52.3$)$ & \\
\hline Age (years) & 45.5 (44.6 to 46.4 ) & 59.1 (58.1 to 60.0$)$ & $<0.001$ \\
\hline \multicolumn{4}{|l|}{ Race } \\
\hline Non-Hispanic white (\%) & 66.4 (60.8 to 71.9$)$ & 65.1 (58.6 to 71.5$)$ & 0.025 \\
\hline Non-Hispanic black (\%) & 10.7 (7.8 to 13.7$)$ & 13.1 (9.8 to 16.4$)$ & \\
\hline Mexican American (\%) & $8.4(5.7$ to 11.1$)$ & 9.0 (5.6 to 12.5$)$ & \\
\hline Other (\%) & 14.5 (12.0 to 16.9$)$ & 12.8 (9.6 to 16.1$)$ & \\
\hline \multicolumn{4}{|l|}{ Education† } \\
\hline$\leq$ High school diploma (\%) & 35.3 (30.3 to 40.3$)$ & 42.9 (38 to 47.9$)$ & 0.010 \\
\hline >High school diploma (\%) & 64.7 (59.7 to 69.7$)$ & 57.1 (52.1 to 62$)$ & \\
\hline \multicolumn{4}{|l|}{ Incomeł } \\
\hline$<3$ times the poverty rate $(\%)$ & 50.6 (45.8 to 55.4$)$ & 55.2 (48.9 to 61.6$)$ & 0.159 \\
\hline$\geq 3$ times the poverty rate $(\%)$ & 49.4 (44.6 to 54.2$)$ & 44.8 (38.4 to 51.1$)$ & \\
\hline \multicolumn{4}{|l|}{ Food security§ } \\
\hline Full food security (\%) & 74.5 (71.8 to 77.3$)$ & $68.8(63.2$ to 74.5$)$ & 0.046 \\
\hline Marginal to very low food security (\%) & 25.5 (22.7 to 28.2$)$ & 31.2 (25.5 to 36.8$)$ & \\
\hline Routine place to go for healthcare (\%) & 81.5 (79.6 to 83.4$)$ & 92.1 (89.8 to 94.3 ) & $<0.001$ \\
\hline \multicolumn{4}{|l|}{ Diabetes } \\
\hline Self-reported diabetes (\%) & & 64.6 (60.5 to 68.8$)$ & \\
\hline Time since diagnosis (years) & & 7.1 (6.5 to 7.7$)$ & \\
\hline \multicolumn{4}{|l|}{ Medication use } \\
\hline Insulin use (\%) & & 34.0 (29.4 to 38.7$)$ & \\
\hline Any diabetes medication (\%) & & 61.8 (57.3 to 66.2$)$ & \\
\hline \multicolumn{4}{|l|}{ Blood pressure } \\
\hline Systolic blood pressure (mm Hg) & 120.5 (119.8 to 121.2$)$ & 130.5 (128.9 to 132.2$)$ & $<0.001$ \\
\hline Diastolic blood pressure $(\mathrm{mm} \mathrm{Hg})$ & 68.9 (68.2 to 69.6$)$ & 69.5 (68.4 to 70.7 ) & 0.269 \\
\hline Hypertensive (\%) & 29.9 (27.5 to 32.3$)$ & 68.2 (63.1 to 73.2$)$ & $<0.001$ \\
\hline \multicolumn{4}{|l|}{ Cholesterol } \\
\hline $\mathrm{HDL}(\mathrm{mg} / \mathrm{dL})$ & 55.8 (54.9 to 56.6$)$ & 49.8 (48.3 to 51.3$)$ & $<0.001$ \\
\hline LDL (mg/dL) & 113.4 (111.9 to 114.8$)$ & 105.9 (102.8 to 108.9$)$ & $<0.001$ \\
\hline Total cholesterol (mg/dL) & 190.9 (189.2 to 192.6$)$ & $185.3(181.1$ to 189.5$)$ & 0.012 \\
\hline Triglycerides (mg/dL) & 109.7 (106.6 to 112.9 ) & 152.6 (138.2 to 167.0$)$ & $<0.001$ \\
\hline
\end{tabular}

Bold text indicates statistical significance at the $\mathrm{P}<0.05$ level.

*Values are percent or means $(95 \% \mathrm{Cls})$.

†Data missing for two participants.

†Data available for $92.4 \%$ of participants.

§Data available for $98.4 \%$ of participants.

HDL, high-density lipoprotein; LDL, low-density lipoprotein; NHANES, National Health and Nutrition Examination Survey.

for micronutrients and fiber was performed by dividing absolute intake by total energy intake and multiplying by 2000 to obtain intake per $2000 \mathrm{kcal}$.

The main analysis compared energy-adjusted dietary intakes of those with and without diabetes. Secondary analyses compared absolute dietary intakes of those with and without diabetes and absolute and energy-adjusted dietary intakes by the categories of HbA1c level described above. Pairwise comparisons were performed only after a statistically significant global test. Subgroup analyses 


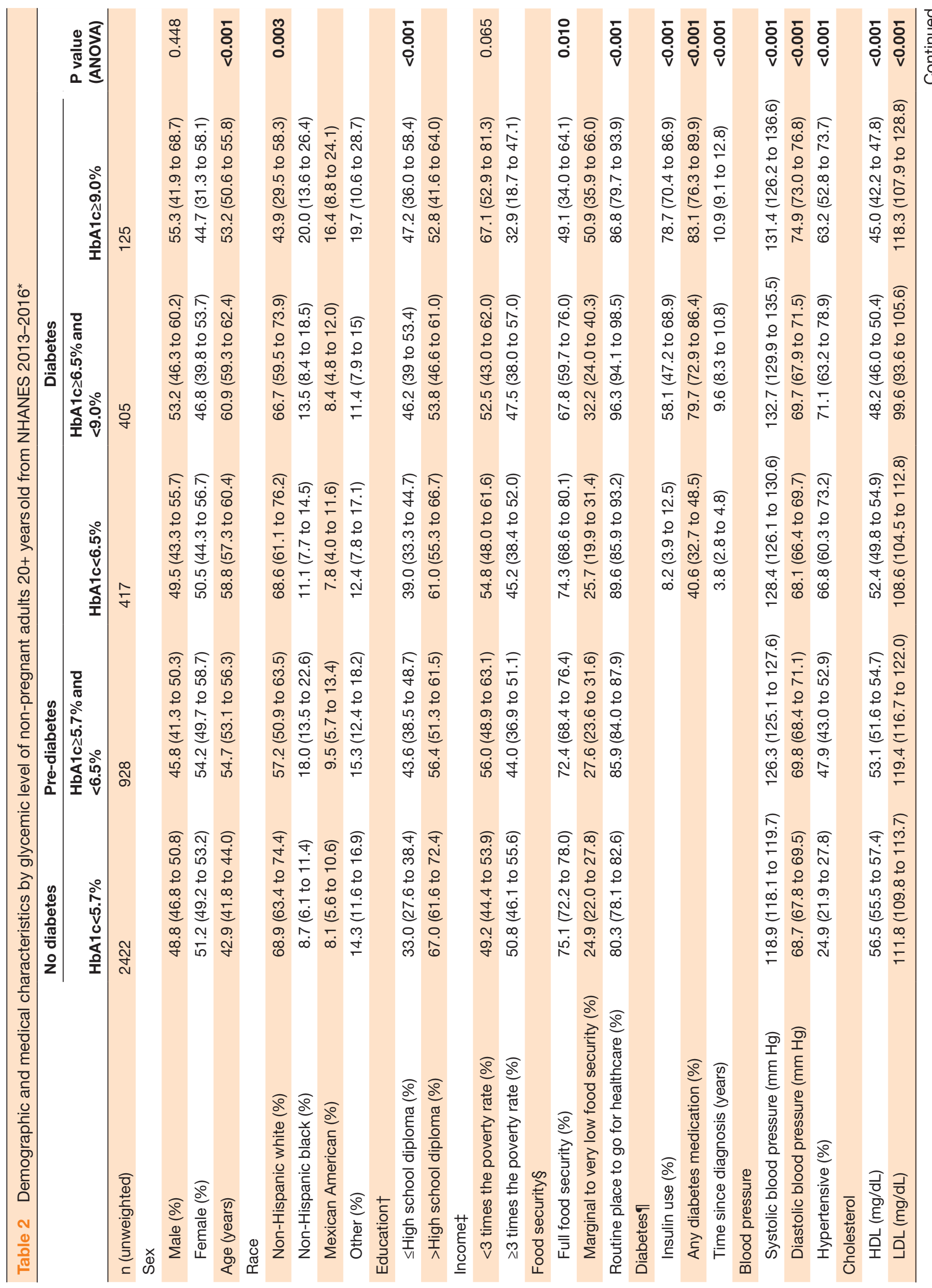




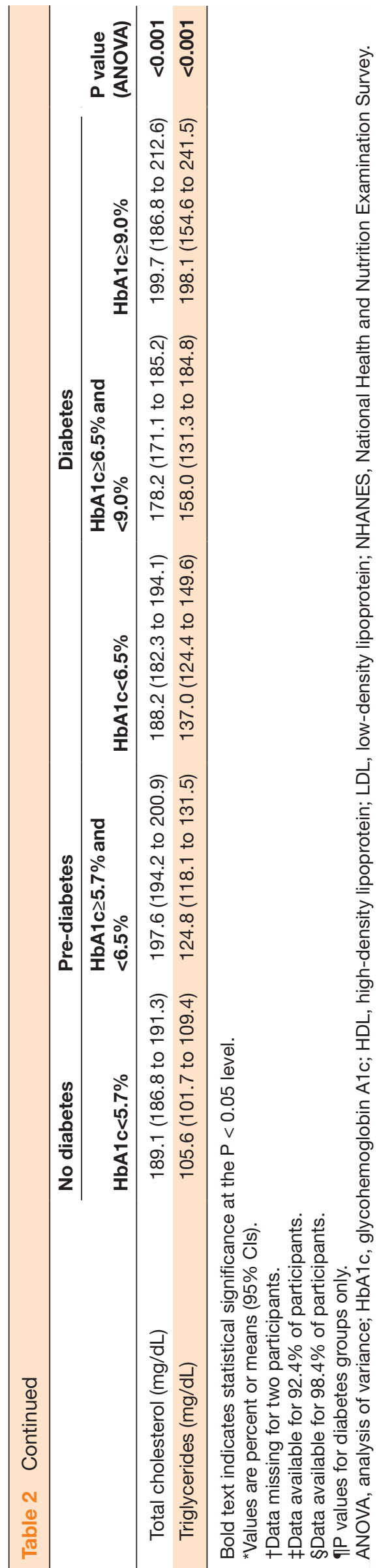

were performed by stratifying by, but not adjusting for, age, race, and sex for both absolute and energy-adjusted intake. An additional subgroup analysis was performed comparing those with prior knowledge of their diabetes status (self-reported diagnosis, use of insulin, or use of other diabetes medication) at the time of the examination compared with those diagnosed during the examination.

\section{RESULTS \\ Baseline characteristics}

There were 947 individuals with diabetes, representing $17.5 \%$ of the unweighted study population. Compared with those without diabetes, those with diabetes were older, less likely to have more than a high school diploma (table 1). Those with diabetes were less likely to have full food security, and more likely to have a routine place to go for healthcare. Those with diabetes had higher systolic, but not diastolic blood pressure, and were more likely to have hypertension. Those with diabetes had lower HDL, LDL, and total cholesterol, but higher triglycerides. About two-thirds of those with diabetes had a self-reported diagnosis of diabetes, the others mainly had a laboratory test (fasting blood glucose, OGTT, or HbA1c) consistent with diabetes. Nearly two-thirds of persons with diabetes self-reported use of at least one diabetes medication, and about a third reported using insulin.

Among those with diabetes, those with an HbAlc greater than $9.0 \%$ were different from those with HbAlc less than $6.5 \%$ on several dimensions (table 2). Those with an HbA1c greater than $9.0 \%$ had longer disease duration, were twice as likely to report using some diabetes medication, and nearly 10 times more likely to report using insulin than those with an HbAlc less than $6.5 \%$. They were younger, less likely to be white, and less likely to have full food security than those with an HbA1c less than $6.5 \%$. Those with an HbAlc greater than 9.0\% had lower HDL, and higher LDL, total cholesterol, and triglycerides than those with an HbA1c less than $6.5 \%$.

\section{Dietary intake}

There were no significant differences in energy-adjusted macronutrient intake between those with and without diabetes (table 3). Both groups consumed about $16 \%$ of calories from protein, $35 \%$ of calories from fat, and $47 \%$ of calories from total carbohydrates. In both groups, total sugar accounted for about $20 \%$ of calories, and unsaturated fat accounted for about $20 \%$ of calories. Both groups consumed about $16 \mathrm{~g}$ of fiber per $2000 \mathrm{kcal}$. Those with diabetes consumed about $7 \%$ more calcium $(988 \mathrm{mg} /$ day $)$ and about $5 \%$ more sodium $(3607 \mathrm{mg} /$ day $)$ than those without diabetes ( $\mathrm{p}=0.033$ and 0.026 , respectively). Among those with diabetes, those with an HbAlc greater than $9.0 \%$ consumed about $4 \%$ less magnesium than those with an HbAlc less than $6.5 \%$ and had a significantly lower overall HEI-2015 diet score (table 4). There were no consistent, statistically significant, or clinically relevant differences in absolute dietary 


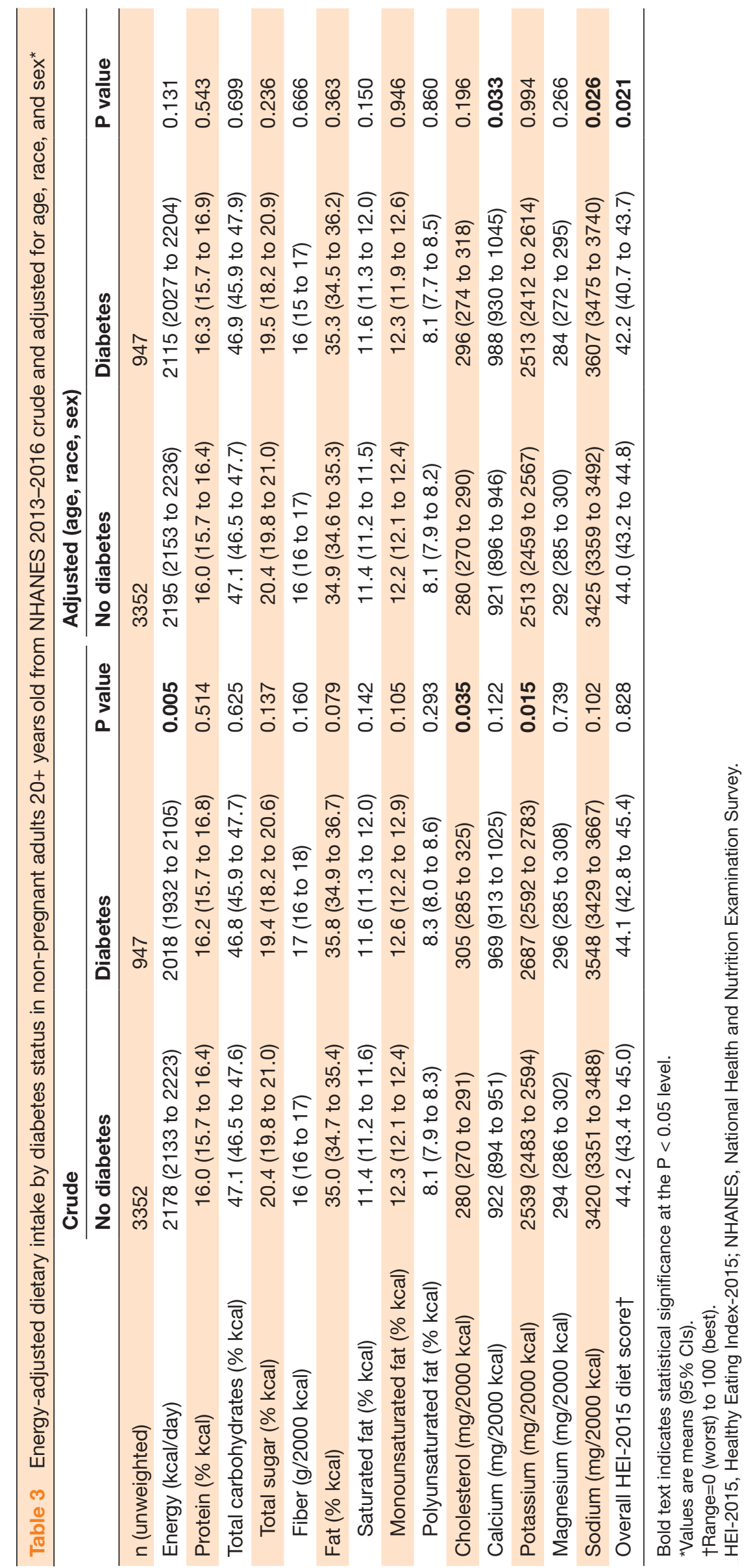




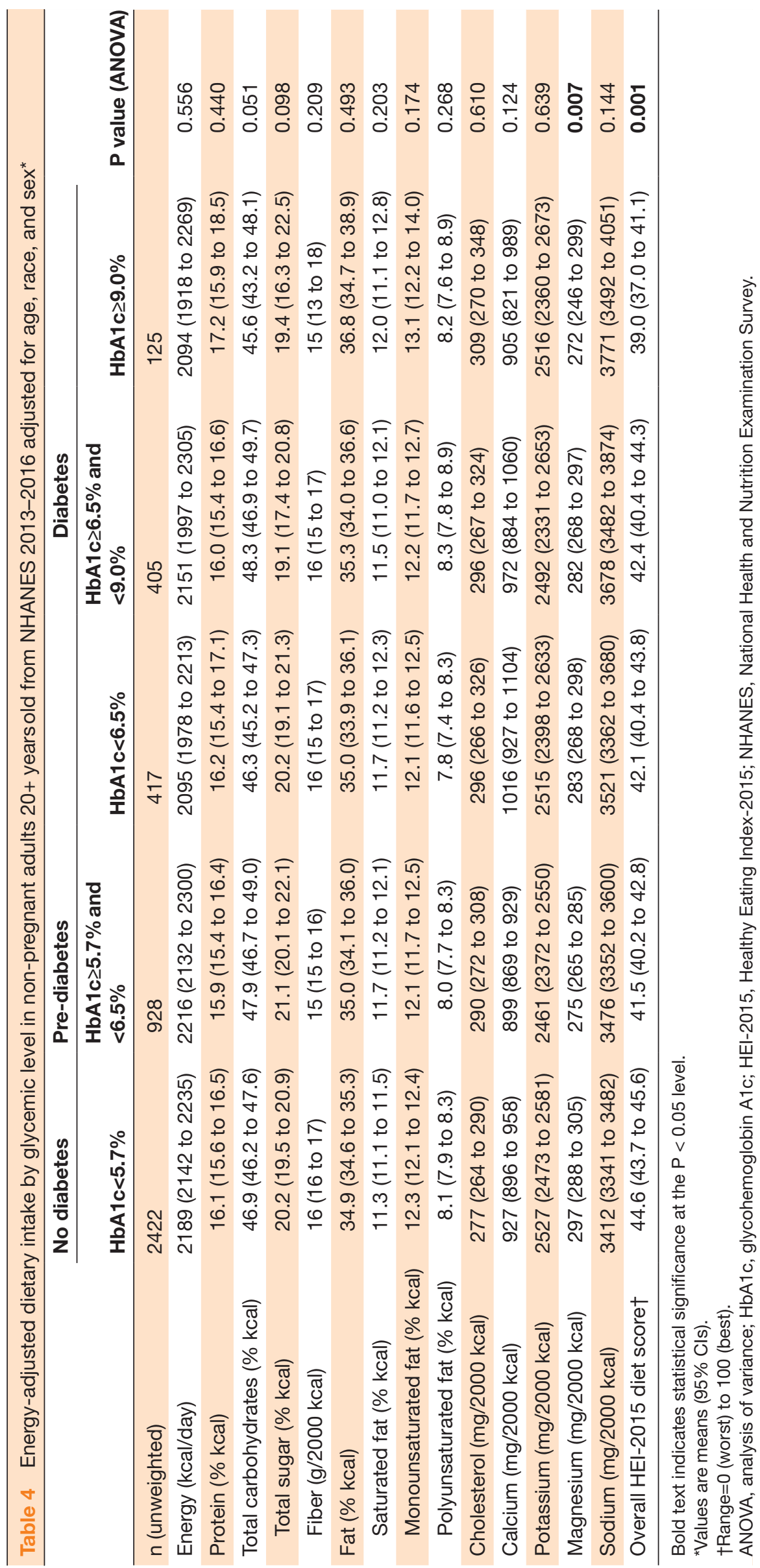


intake between those with and without diabetes or across levels of HbA1c (online supplemental tables 1-3). Further adjustment for education, access to healthcare, and duration of diabetes yielded similar results as adjusting for age, race, and sex alone (online supplemental table 1). Those with diabetes had a lower overall HEI-2015 diet score than those without diabetes.

\section{Subgroup analysis}

Men with diabetes consumed fewer calories, carbohydrates (specifically sugar), and less magnesium overall compared with men without diabetes (online supplemental table 4). Men with diabetes had higher energy-adjusted cholesterol and potassium intake than men without diabetes. Women with diabetes consumed fewer calories, potassium, and magnesium overall compared with women without diabetes. Women with diabetes did not have statistically significantly different energy-adjusted macronutrient and micronutrient intake than women without diabetes. There were no consistent differences in dietary intake (absolute or energy adjusted) comparing those with and without diabetes by age group or race (online supplemental tables 5-8). Among those with diabetes, there were no consistent differences in dietary intake (absolute or energy adjusted) or diet quality comparing those with and without prior knowledge of their diabetes status (online supplemental table 9).

\section{DISCUSSION}

In this nationally representative sample, there were no substantial or consistent differences in the dietary intake of macronutrients or micronutrients between US adults with and without diabetes. Similarly, macronutrient intake did not vary consistently by HbAlc level or by diabetes status within strata of age, race, and sex. Furthermore, we did not find significant differences in carbohydrate intake (total carbohydrates, sugar, or fiber) between those with or without diabetes. These results suggest that those with diabetes are not consuming significantly different macronutrients or micronutrients than those without diabetes. However, those with diabetes had lower diet quality and were less likely to have full food security with fewer than half of those with HbAlc $>9.0 \%$ having full food security.

To our knowledge, we provide the first report on direct comparisons between the diets of those with and without diabetes among US adults. An analysis of longitudinal dietary trends from 1988 to 2012 using NHANES showed that, over the last few decades, patients both with and without diabetes consumed less fiber and more sodium, calcium, and cholesterol. ${ }^{17} \mathrm{~A}$ recent systematic review analyzed 11 studies (after screening roughly 12000 ) and found that those with diabetes do not meet recommendations for specific food groups. ${ }^{5}$ They consumed, on average, $0.5-2.5$ servings a day under the nationally recommended amounts of fruits, vegetables, dairy, and grains and more than a serving a day over the recommended amounts of meat. ${ }^{5}$

Strengths of this study include the use of a large, nationally representative survey. This allowed analysis of dietary intake both by diabetes status and across the spectrum of diabetes based on HbA1c. In the overall analyses, as well as subgroup analyses, there was adequate statistical power as indicated by small CIs around mean estimates. This study also has several limitations. First, NHANES does not distinguish between type 1 and type 2 diabetes. However, in the USA, approximately $90 \%-95 \%$ of patients with diabetes have type 2 diabetes. ${ }^{18}$ Hence, we report the dietary intake of adults with diabetes. Second, we analyzed mean estimates of intake using a single dietary recall, rather than individuals' usual intake. Third, given that NHANES is a cross-sectional survey, we were unable to evaluate changes in diet before and after the diagnosis of diabetes. However, among those with diabetes, there were not consistent differences in the diets among those with and without knowledge of their diabetes status at the NHANES examination.

Future studies should incorporate community-level food environment data to understand the contribution of access to nutrient-dense foods to dietary patterns among people with and without diabetes. Also, longitudinal studies could be valuable to track if the diets of those with diabetes significantly change after diagnosis. ${ }^{19}$ Our study also highlights the importance of including persons with diabetes in dietary intervention studies, to ensure that broad population-based recommendations reflect the needs of this group.

While previous dietary recommendations were often nutrient focused, both the ADA and the USDA's recent recommendations increasingly focus on a broader approach. ${ }^{1-3}$ These results further support this general approach to encourage a variety of healthful eating patterns emphasizing a variety of options, rather than a prescriptive diabetes-specific diet. ${ }^{13}$ Implementing this approach in the population will likely require enhanced targeted efforts to improve the dietary intake of persons with diabetes, as well as broad efforts to improve the dietary intake of the general population.

\section{Author affiliations}

${ }^{1}$ Department of Public Health, Shenandoah University, Winchester, Virginia, USA

${ }^{2}$ Institute for Clinical and Translational Research, Johns Hopkins School of

Medicine, Baltimore, Maryland, USA

${ }^{3}$ Division of General Internal Medicine, Department of Medicine, Johns Hopkins School of Medicine, Baltimore, Maryland, USA

${ }^{4}$ Welch Center for Prevention, Epidemiology, and Clinical Research, Johns Hopkins University, Baltimore, Maryland, USA

${ }^{5}$ Department of Epidemiology, Johns Hopkins University, Baltimore, Maryland, USA

Contributors LJA, SJP, NMM, KW, BW, HCY, ERM, HS, SO, and STM gave input on the design of analysis and wrote the paper. STM analyzed data.

Funding The authors have not declared a specific grant for this research from any funding agency in the public, commercial or not-for-profit sectors.

Competing interests None declared.

Patient consent for publication Not required.

Ethics approval NHANES approved this study under NCHS Research Ethics Review Board (ERB) Protocol № 2011-17.

Provenance and peer review Not commissioned; externally peer reviewed

Data availlability statement Data are available in a public, open access repository. National Health and Nutrition Examination Survey, https://wwwn.cdc. gov/nchs/nhanes/ 
Supplemental material This content has been supplied by the author(s). It has not been vetted by BMJ Publishing Group Limited (BMJ) and may not have been peer-reviewed. Any opinions or recommendations discussed are solely those of the author(s) and are not endorsed by BMJ. BMJ disclaims all liability and responsibility arising from any reliance placed on the content. Where the content includes any translated material, BMJ does not warrant the accuracy and reliability of the translations (including but not limited to local regulations, clinical guidelines, terminology, drug names and drug dosages), and is not responsible for any error and/or omissions arising from translation and adaptation or otherwise.

Open access This is an open access article distributed in accordance with the Creative Commons Attribution Non Commercial (CC BY-NC 4.0) license, which permits others to distribute, remix, adapt, build upon this work non-commercially, and license their derivative works on different terms, provided the original work is properly cited, appropriate credit is given, any changes made indicated, and the use is non-commercial. See: http://creativecommons.org/licenses/by-nc/4.0/.

ORCID iDs

Scott T McClure http://orcid.org/0000-0002-9752-3152

Scott Jordan Pilla http://orcid.org/0000-0002-3292-9047

Hsin-Chieh Yeh http://orcid.org/0000-0002-5738-0652

\section{REFERENCES}

1 American Diabetes Association. 5. Lifestyle management: standards of medical care in diabetes-2019. Diabetes Care 2019;42:S46-60.

2 United States Department of Agriculture. 2015-2020 dietary guidelines for Americans. 8 edn, 2014. http://health.gov/ dietaryguidelines/2015/guidelines/

3 American Diabetes Association. 5. Facilitating Behavior Change and Well-being to Improve Health Outcomes: Standards of Medical Care in Diabetes-2020. Diabetes Care 2020;43:S48-65.

4 Rehm CD, Peñalvo JL, Afshin A, et al. Dietary intake among US adults, 1999-2012. JAMA 2016;315:2542-53.

5 Burch E, Ball L, Somerville M, et al. Dietary intake by food group of individuals with type 2 diabetes mellitus: a systematic review. Diabetes Res Clin Pract 2018;137:160-72.
6 Jaacks LM, Du S, Mendez MA, et al. Comparison of the dietary intakes of individuals with and without type 1 diabetes in China. Asia Pac J Clin Nutr 2015;24:639-49.

7 Lloyd-Jones DM, Hong Y, Labarthe D, et al. Defining and setting national goals for cardiovascular health promotion and disease reduction: the American heart association's strategic impact goa through 2020 and beyond. Circulation 2010;121:586-613.

8 Menke A, Casagrande S, Geiss L, et al. Prevalence of and trends in diabetes among adults in the United States, 1988-2012. JAMA 2015;314:1021-9.

9 Khayyatzadeh SS, Moohebati M, Mazidi M, et al. Nutrient patterns and their relationship to metabolic syndrome in Iranian adults. Eur J Clin Invest 2016;46:840-52.

10 Fang $\mathrm{X}$, Han H, Li M, et al. Dose-Response relationship between dietary magnesium intake and risk of type 2 diabetes mellitus: a systematic review and meta-regression analysis of prospective cohort studies. Nutrients 2016;8. doi:10.3390/nu8110739. [Epub ahead of print: 19 Nov 2016]

11 Chatterjee R, Yeh $\mathrm{H}-\mathrm{C}$, Shafi T, et al. Serum and dietary potassium and risk of incident type 2 diabetes mellitus: the Atherosclerosis risk in communities (ARIC) study. Arch Intern Med 2010;170:1745-51.

12 Krebs-Smith SM, Pannucci TE, Subar AF, et al. Update of the healthy eating index: HEl-2015. J Acad Nutr Diet 2018;118:1591-602.

13 Bowman S, Clemens J, Friday J, et al. Food patterns equivalents database 2015-2016. Food Surv Res 2017.

14 Bowman S, Clemens J, Friday J, et al. Food patterns equivalents database 2013-2014. Food Surv Res 2017.

15 Bickel G, Nord M, Price C, et al. Guide to measuring household food security, revised 2000. Alexandrea, Va, 2000. Available: http://www. fns.usda.gov/oane

16 Friedewald WT, Levy RI, Fredrickson DS. Estimation of the concentration of low-density lipoprotein cholesterol in plasma, without use of the preparative ultracentrifuge. Clin Chem 1972;18:499-502.

17 Casagrande SS, Cowie CC. Trends in dietary intake among adults with type 2 diabetes: NHANES 1988-2012. J Hum Nutr Diet 2017;30:479-89.

18 Centers for Disease Control and Prevention. Type 2 diabetes, 2019. Available: https://www.cdc.gov/diabetes/basics/type2.html

19 Burch E, Williams LT, Makepeace $\mathrm{H}$, et al. How does diet change with a diagnosis of diabetes? protocol of the 3D longitudinal study. Nutrients 2019;11:158-15. 